\title{
CMEARTICLE
}

\section{Approach to infantile colic in primary care}

Teck Meng Lawrence $\underline{\operatorname{Lam}}^{1}$, MBBS, Poh Chong $\underline{\text { Chan }}{ }^{2}$, MMed, MRCPCH, Lay Hoon $\underline{G o h}^{1}$, MMed, FCFP

\begin{abstract}
Ms Sally Tan, a first-time mother, took her two-month-old baby boy Ayden to see you, their family doctor. Ayden had been crying incessantly for the past two weeks and Sally was at her wits' end. She said that Ayden usually cried for 3-4 hours in the evenings, causing a lot of frustration for Sally and her husband, as they were unable to find the reason for his crying and could not console Ayden. Sally was keen to try oral simethicone because she had read online that it was effective.
\end{abstract}

\section{WHAT IS INFANTILE COLIC?}

Colic or excessive crying is a common benign, self-limiting condition that can occur in $40 \%$ of infants. ${ }^{(1,2)}$ Although it is one of the most distressing problems of infancy, ${ }^{(2-4)}$ it has no clear cause, no gold standard remedy or preventative action. ${ }^{(5,6)}$ It is common for infants to cry more during the first three months of life, with a mean duration of crying of two hours per day. ${ }^{(2)}$ When the baby is aged 10-12 weeks, the mean duration of crying decreases to an hour per day, but variations can occur. ${ }^{(2)}$ Unfortunately, there is no clinically useful definition of excessive crying. ${ }^{(3,5)}$ The Rome IV criteria define infant colic as a functional gastrointestinal disorder from birth to five months of age, fulfilling the conditions in Box 1. However, the Rome IV criteria is primarily used for academic purposes. ${ }^{(4)}$

Wessel's criteria is more useful for clinical purposes; it defines colic as crying for no apparent reason lasting for more than three hours per day, for more than three days per week, for longer than three weeks (Box 2). ${ }^{(1)}$

\section{HOW RELEVANT IS THIS TO MY PRACTICE?}

It is worth noting that while colic is common, many infants do not fulfil all three criteria strictly. Family physicians should be aware of parental perception and coping when assessing the infant. ${ }^{(2-5)}$ Especially in our local context where infants may have more than one caregiver, colic can refer to crying that is causing distress to

\section{Box 1. Rome IV criteria for infantile colic:}

1. Age of baby $<5$ months when symptoms start and stop.

2. Recurrent and prolonged periods of crying, fussing or irritability that start and stop without obvious cause and cannot be prevented or resolved by caregivers.

3. No evidence of failure to thrive, fever or illness.

4. Caregiver reports crying/fussing for $>3$ hours per day or $>3$ days a week.

5. Total daily crying is confirmed to be $>3$ hours when measured by at least one prospectively kept 24-hour diary. caregivers. Often, the diagnosis of colic can be provided to the family once other possible causes are excluded. The features of paroxysms, qualitative differences in crying and hypertonia can be used to distinguish colic from normal crying.

\section{Paroxysms}

Episodes usually happen in the evening hours and are unrelated to the baby's prior activity. They often occur suddenly, and have a clear beginning and end. ${ }^{(5,7)}$ Crying usually peaks at about 6-8 weeks of age and improves by $3-4$ months of age.

\section{Qualitative differences in the crying}

Colic differs from normal crying, as it is usually louder, more intense and higher pitched. ${ }^{(3)}$ Infants may sound like they are screaming, and parents often are unable to console or settle their baby during a bout of colic.

\section{Hypertonia}

Infants may experience tensing of the abdomen, arching of the back, clenching, stiffening of the arms and drawing up of legs. ${ }^{(8)}$ The following red flags should be ruled out during assessment: ${ }^{(7)}$ (a) fever; (b) lethargy; (c) excessive vomiting; (d) distended abdomen; and (e) poor feeding or weight loss. Important surgical causes such as intestinal obstruction, volvulus, incarcerated hernia and intussusception should be considered for infants with distended abdomen and vomiting. Fever, lethargy and poor feeding usually indicate an underlying infection and should be further investigated. If such symptoms are present, family physicians must decide if the infant can be managed in primary care or should be promptly referred to the emergency department. ${ }^{(8)}$

\section{Box 2. 'Rule of three' diagnostic criteria for colic:}

Crying for

$\cdot>3$ hours per day

$\cdot>3$ days per week

$\cdot>3$ weeks

${ }^{1}$ Department of Family Medicine, National University Health System, ${ }^{2}$ Khoo Teck Puat-National University Children's Medical Institute, National University Hospital, Singapore Correspondence: Dr Teck Meng Lawrence Lam, Resident, Department of Family Medicine, National University Health System, 1 E Kent Ridge Road, NUHS Tower Block, Level 9 , Singapore 119228. Lawrence_lam@nuhs.edu.sg 
Table I. Probable causes of infantile colic.

\begin{tabular}{|c|c|}
\hline Category & Causes \\
\hline Non-pathological causes of crying & $\begin{array}{l}\text { 1. Lack of sleep } \\
\text { Average sleep requirements: } \\
\text { - Birth to } 2 \text { months: } 16 \text { hours/day } \\
\text { - } 2-3 \text { months: } 15 \text { hours/day } \\
\text { 2. Hunger } \\
\text { - Frequent feeding (<3 hourly), inadequate milk supply } \\
\text { 3. Discomfort arising from soiled diapers, nappy rash, extreme temperatures, or sudden stimulation of } \\
\text { noise or light } \\
\text { These factors can be explored first before moving onto other causes. }\end{array}$ \\
\hline Psychosocial & Parental variables, e.g. family stress, maternal anxiety ${ }^{(1)}$ \\
\hline Gastrointestinal & $\begin{array}{l}\text { 1. Faulty feeding techniques (i.e. underfeeding, overfeeding, infrequent burping, swallowed air) } \\
\text { 2. Cow's milk protein intolerance } \\
\text { 3. Lactose intolerance } \\
\text { 4. Gastro-oesophageal reflux }\end{array}$ \\
\hline
\end{tabular}

\section{WHAT CAN I DO IN MY PRACTICE? Explore common causes of crying}

There are no clear risk factors or causes for infantile colic. The incidence of colic has no relationship to gender, being breast-fed or formula-fed, and being full-term or preterm. ${ }^{(7)}$ Table I shows the most probable causes of infantile colic but it is important to note that most infants have no organic cause for crying. ${ }^{(8,9)}$

For infants who are aged 6-8 weeks, normal feeding frequency is about three hours for both breastfeeding and bottle-feeding. Cow's milk allergies are usually delayed nonimmunoglobulin E-mediated reactions and should be considered if there is vomiting, blood or mucus in diarrhoea and failure to thrive. ${ }^{(4,7)}$ Lactose intolerance should be suspected if the diarrhoea is watery and frothy. A family history of atopy is associated with milk allergies.

Gastro-oesophageal reflux can manifest as feeding difficulties and vomiting, especially after feeds, due to oesophagitis. Gastro-oesophageal reflux is physiological, and up to $50 \%$ of infants below two months of age regurgitate at least twice per day but will outgrow their symptoms by 12 months of age. ${ }^{(4)}$ In contrast, gastro-oesophageal reflux disease is associated with significant vomiting ( $>4$ times per day), feeding refusal and failure to thrive.

\section{Approach to history and examination}

A comprehensive history of the caregiving of the child should be obtained, including feeding, sleeping and toileting patterns. It is important to elicit this history from the main caregiver, who may not always be the parents. Family physicians should be suspicious if there are associated gastrointestinal symptoms such as vomiting or bloody stools, which suggest gastro-oesophageal reflux and cow's milk intolerance, respectively. Medication or drug use in the infant or mother should be considered. Psychosocial history is crucial, including the perceptions and interactions of extended family members, especially in the local context. It is also important to find out if the mother is breastfeeding or bottle-feeding and the volume of feeds the infant is receiving. Ask for symptoms of poor latch or milk supply and frequency of feeding. As the parents may be at risk of burnout, it is recommended to find out how they are coping and if there is additional help at home.

The pattern of the infant's crying should be elicited, especially its timing and relationship to feeding, duration and normal feeding practices. Information on parental coping and techniques used by parents to settle infants during a bout of colic is useful later when offering parentcraft advice.

During the examination, the infant's height, weight and head circumference should be plotted to assess growth trajectory. Observe how the parents interact with the infant during a bout of colic and what soothing techniques they use. Assess the infant's fontanelle and hydration status and any presence of tongue tie or oral thrush that may affect feeding. Cardiovascular examination should be performed for congenital malformations or heart failure, and a systemic examination for any signs of infection (e.g. otitis media, meningitis). Evaluate the abdomen for tenderness and masses. Inspect the perineum for diaper rash and hernias and, in a male infant, examine for testicular torsion. Lastly, examine for any trauma or foreign body (e.g. in the eye).

\section{Parental support}

Parental support by the family physician remains the mainstay of therapy. ${ }^{(3,4,6,7)}$ Reassure the parents that infant colic is normal and not harmful to the baby in the short or long term. The natural progression of colic is to resolve with time, usually peaking at six weeks of age and resolving by 10-12 weeks of age. Firstline interventions include mitigating any contributing factors, addressing feeding problems and experimenting with various options. Educate the parent to look out for red flags and to return to the clinic promptly if these are present.

Parentcraft advice and counselling to parents include the following: check whether your baby is comfortable (e.g. check baby's temperature, whether nappy requires changing, or offering feed if last feed was more than two hours ago); provide a pacifier; swaddle your baby; walk and rock your baby; massage your baby's belly; change your baby's bottle; switch breasts if breastfeeding; feed in an inclined position 
Table II. Evidence-based recommendations for parents of infants..$^{(6,7,10,13-15)}$

\begin{tabular}{|ll|}
\hline Breastfeeding infants & Bottle-fed infants \\
\hline Parental reassurance & Parental reassurance \\
\hline First line: Parentcraft advice & First line: Parentcraft advice \\
\hline $\begin{array}{l}\text { Second line: Consider an allergen-restricted diet for } \\
\text { mothers with a history of food intolerance or allergies, } \\
\text { or consider giving Lactobacillus reuteri for infants. }\end{array}$ & $\begin{array}{l}\text { Second line: Consider a trial of transition to hydrolysed formula for } 2 \text { weeks and } \\
\text { revert to the original formula if there is no improvement. }\end{array}$ \\
$\begin{array}{l}\text { Allergen-restricted diet: exclude cow's milk, eggs, } \\
\text { peanuts, tree nuts, wheat and soy. }\end{array}$ & $\begin{array}{l}\text { For infants with cow's milk protein intolerance, a clinical response usually } \\
\text { occurs within 48 hours after changing to hydrolysed formula. However, } \\
\text { hydrolysed formula is much more expensive and should not be recommended } \\
\text { unless the allergy is assessed and proven by a paediatrician. It can then } \\
\text { be continued until 3-6 months of age. If there is no improvement in colic } \\
\text { symptoms after two weeks, parents should switch back to the original formula. }\end{array}$ \\
\hline
\end{tabular}

and burp the baby often; reduce stimulation and use gentle, regular white noise; give your baby a warm bath; breastfeed; take adequate breaks from caregiving; and participate in social support groups.

In many cases, parents just require reassurance regarding the infant's health and their own competency, while the colic will resolve with time. The role of the family physician is to acknowledge the challenges the parents are facing and ensure that they have adequate support and rest. Postnatal depression is common in mothers of babies with infantile colic and physicians should be alert to possible signs of maternal depression or non-accidental injuries in infants. Depending on the symptom onset, expected resolution and family dynamics, follow-up appointments should be scheduled to monitor for resolution.

\section{Evidence-based recommendations}

Table II shows recommendations for parents of breastfed and bottle-fed infants. Additionally, there is some evidence that Lactobacillus reuteri, given as an oral drop, improved colic symptoms with no adverse side effects for breastfed infants. ${ }^{9,11,12}$ However, this is not recommended for formula-fed infants, as Lactobacillus reuteri may worsen colic symptoms for bottle-fed infants. ${ }^{(7,9)}$ There is no evidence in favour of soy-based formulas and soy may be potentially harmful when used for infantile colic, as it can act as an allergen. ${ }^{(7)}$

In a randomised controlled study, a low-allergen diet for mothers improved colic symptoms among breastfed infants, and this was backed by a systematic review. ${ }^{(10,13)}$ Breastfeeding mothers should obtain adequate nutrition and can resume a normal diet after 3-6 months of breastfeeding. ${ }^{(7)}$ They should also be reassured that the prevalence of colic is similar between breastfed and bottle-fed infants. ${ }^{(7,10)}$

\section{Unproven interventions Pharmacological}

Simethicone is an oral suspension that is often used for the relief of infantile colic, with some success. ${ }^{(5)}$ Over $90 \%$ of parents reported improvement of symptoms, some even within an hour. ${ }^{(5)}$ However, a systematic review found that it is no better than a placebo. ${ }^{(14)}$ Despite this, oral simethicone is readily available as an over-the-counter remedy and there is anecdotal evidence for symptom relief or placebo effect. ${ }^{(5,15)}$

\section{Herbal remedies}

To date, there is no evidence that herbal remedies work. ${ }^{(6)} \mathrm{Herbal}$ remedies should not be given as there are potential risks of side effects, which may interfere with the infant's feeding.

\section{Massage and manipulative therapies}

There is currently no evidence that massage improves infant colic and it may overstimulate colicky infants. ${ }^{(6)}$ However, infant massage promotes parent-infant bonding and can be encouraged. Acupuncture has also not been proven to have any benefits and more studies are required. ${ }^{(16)}$

\section{TAKE HOME MESSAGES}

1. Infant colic is a benign, self-limiting condition that affects up to $40 \%$ of infants during the first three months of life.

2. The peak onset of colic occurs at age 6-8 weeks and it usually resolves by age 10-12 weeks.

3. A comprehensive history and examination should be performed to rule out red flags such as abdominal distension, fever, poor feeding and lethargy.

4. The mainstay of treatment is use of parentcraft and support from the family physician.

5. Formula changes are not helpful unless there is a proven allergy or intolerance.

Sally returned to your clinic six weeks later, relieved that Ayden's symptoms had improved. Your reassurance for Sally and her husband had helped them to cope during this stressful period. Simple measures such as swaddling, massaging and changing Ayden's feeding posture had alleviated his colic without the need for oral simethicone. Sally said she felt more comfortable caring for Ayden and was glad that he was now a happy and growing baby. 
ABSTRACT Infantile colic is a common self-limiting condition that causes significant distress to parents and caregivers. There is no clear cause, gold standard remedy or preventative action. The role of the family physician is to rule out sinister causes while providing counselling and reassurance for parents. The mainstay of management is parental support and reassurance while looking out for red flags in the baby such as fever, lethargy, distended abdomen and failure to thrive. This article provides a framework to approaching infantile colic and practical pointers to share with parents.

Keywords: approach, colic, excessive crying, infant, infantile colic

\section{REFERENCES}

1. Wessel MA, Cobb JC, Jackson EB, Harris GS Jr, Detwiler AC. Paroxysmal fussing in infancy, sometimes called colic. Pediatrics 1954; 14:421-35.

2. Wolke D, Bilgin A, Samara M. Systematic review and meta-analysis: fussing and crying durations and prevalence of colic in infants. J Pediatr 2017; 185:55-61.e4.

3. Barr RG. Normality: a clinically useless concept. The case of infant crying and colic. J Dev Behav Pediatr 1993; 14:264-70.

4. Zeevenhooven J, Koppen IJ, Benninga MA. The new Rome IV criteria fo functional gastrointestinal disorders in infants and toddlers. Pediatr Gastroenterol Hepatol Nutr 2017; 20:1-13.

5. Goldman M, Beaumont T. A real world evaluation of a treatment for infant colic based on the experience and perceptions of 4004 parents. Br J Nurs 2017; 26(5 Suppl 1):S3-S10.

6. Lucassen PL, Assendelft WJ, Gubbels JW, et al. Effectiveness of treatments for infantile colic: systematic review. BMJ 1998; 316:1563-9.

7. Johnson JD, Cocker K, Chang E. Infantile colic: recognition and treatment. Am Fam Physician 2015; 92:577-82

8. The Royal Children's Hospital Melbourne. Unsettled or crying babies (colic). Clinical Practice Guidelines 2012 [online]. Available at: https://www.rch.org. au/clinicalguide/guideline_index/Crying_Baby_Infant_Distress/. Accessed June 29, 2018.

9. Sung V, Collett S, de Gooyer T, et al. Probiotics to prevent or treat excessive infant crying: systematic review and meta-analysis. JAMA Pediatr 2013; 167:1150-7.

10. Hill DJ, Roy N, Heine RG, et al. Effect of a low-allergen maternal diet on colic among breastfed infants: a randomized, controlled trial. Pediatrics 2005; 116:e709-15.

11. Savino F, Pelle E, Palumeri E, Oggero R, Miniero R. Lactobacillus reuteri (American Type Culture Collection Strain 55730) versus simethicone in the treatment of infantile colic: a prospective randomized study. Pediatrics 2007; 119:e124-30

12. Chau K, Lau E, Greenberg S, et al. Probiotics for infantile colic: a randomized, double-blind, placebo-controlled trial investigating Lactobacillus reuteri DSM 17938. J Pediatr 2015; 166:74-8.

13. lacovou M, Ralston RA, Muir J, Walker KZ, Truby H. Dietary management of infantile colic: a systematic review. Matern Child Health J 2012; 16:1319-31.

14. Garrison MM, Christakis DA. A systematic review of treatments for infant colic. Pediatrics 2000; 106(1 Pt 2):184-90.

15. Hall B, Chesters J, Robinson A. Infantile colic: a systematic review of medical and conventional therapies. J Paediatr Child Health 2012; 48:128-37.

16. Landgren K, Hallström I. Effect of minimal acupuncture for infantile colic: a multicentre, three-armed, single-blind, randomised controlled trial (ACU-COL). Acupunct Med 2017; 35:171-9. 


\section{SINGAPORE MEDICAL COUNCIL CATEGORY 3B CME PROGRAMME} (Code SMJ 201901A)

1. Infantile colic is a benign, self-limiting condition.

2. Crying usually peaks at about 6-8 weeks of age and improves by $3-4$ months of age.

3. Infants must fulfil all three of Wessel's criteria for a diagnosis to be made.

4. Patients should be referred to paediatricians for early workup of infantile colic.

5. Imaging studies are required to exclude infantile colic.

6. The prevalence of colic is higher in male infants.

7. Infants who are bottle-fed are at higher risk of developing colic.

8. Parents of breastfed infants with colic should be encouraged to discontinue breastfeeding.

9. Red flags for colic include fever, abdominal distension, poor feeding and failure to thrive.

10. For infants with bloody stools, cow's milk protein intolerance should be considered.

11. Lactobacillus reuteri can be given to breastfeeding infants for colic symptoms.

12. If cow's milk intolerance is suspected, infants can be switched to a trial of soy-based formula.

13. Infants should be fed in an inclined position and burped often.

14. Herbal therapy is effective in alleviating symptoms of colic.

15. Infant massage can promote mother-baby bonding.

16. Oral simethicone is a readily available over-the-counter remedy for the treatment of colic and may be effective.

17. Elimination of allergens (e.g. cow's milk, eggs, fish, peanuts, soy, tree nuts and wheat) from the diet of breastfeeding mothers may relieve colic symptoms.

18. Physicians should consider the impact and perceptions of caregivers when assessing colic.

19. Most cases of colic in infants have an identifiable cause.

20. Parental support and reassurance is the mainstay of therapy.

$\begin{array}{cc}\text { True } & \text { False } \\ \square & \square \\ \square & \square \\ \square & \square \\ \square & \square \\ \square & \square \\ \square & \square \\ \square & \square \\ \square & \square \\ \square & \square \\ \square & \square \\ \square & \square \\ \square & \square \\ \square & \square \\ \square & \square \\ \square & \square \\ \square & \square \\ & \\ \square & \square \\ \square & \square \\ \square & \square \\ \square & \square \\ & \square\end{array}$

\section{Doctor's particulars:}

Name in full:

MCR no.:

Specialty:

Email:

\section{SUBMISSION INSTRUCTIONS:}

Visit the SMJ website: http://www.smj.org.sg/current-issue and select the appropriate quiz. You will be redirected to the SMA login page.

For SMA member: (1) Log in with your username and password (if you do not know your password, please click on 'Forgot your password?'). (2) Select your answers for each quiz and click 'Submit'.

For non-SMA member: (1) Create an SMJ CME account, or login with your SMJ CME username and password (for returning users). (2) Make payment of SGD 21.40 (inclusive of $7 \%$ GST) via PayPal to access this month's quizzes. (3) Select your answers for each quiz and click 'Submit'.

RESULTS:

(1) Answers will be published online in the SMJ March 2019 issue. (2) The MCR numbers of successful candidates will be posted online at the SMJ website by 8 March 2019. (3) Passing mark is $60 \%$. No mark will be deducted for incorrect answers. (4) The SMJ editorial office will submit the list of successful candidates to the Singapore Medical Council. (5) One CME point is awarded for successful candidates. (6) SMC credits CME points according to the month of publication of the CME article (i.e. points awarded for a quiz published in the January 2019 issue will be credited for the month of December 2017, even if the deadline is in January 2018).

Deadline for submission (January 2019 SMJ 3B CME programme): 12 noon, 1 March 2019. 